\title{
Comment on: Cerebrovascular ischaemia after Carbon monoxide intoxication
}

Singapore Med J 2015; 56(3): 175 doi: 10.11622/smedj.2015044

Dear Sir,

Kara et $\mathrm{al}^{(1)}$ provided an excellent case study on carbon monoxide (CO) poisoning. In Table I, the authors indicated a normal range of carboxyhaemologobin ( $\mathrm{HbCO}$ ) of $0 \%-100.0 \%$, which is not accurate. A study ${ }^{(2)}$ has shown a difference in HbCO for smokers and non-smokers, and it may be of value to separate these two groups when discussing an applicable reference range. A suggested $\mathrm{HbCO}$ range for non-smokers is $<2 \%-3 \%$ and that for smokers is $<7 \%-10 \%$. ${ }^{(2-4)}$ The majority $(90 \%)$ of non-smokers and smokers have been found to exhibit an $\mathrm{HbCO}$ level of $<1.33 \%$ and $<7.56 \%$, respectively. ${ }^{(4)}$ Some studies ${ }^{(2,4)}$ have noted that the upper $\mathrm{HbCO}$ level for smokers can exceed $10 \%$ (range 3\%-20\%), indicating an even higher warranted reference range.

Occupational and environmental exposure to $\mathrm{CO}$ can also result in elevated $\mathrm{HbCO}$ levels. ${ }^{(2,5)} \mathrm{CO}$ exposure at the US Occupational Safety and Health Administration Time-Weighted Average Permissible Exposure Limit (50 ppm) has been suggested to result in an $\mathrm{HbCO}$ concentration of $6 \%-8 \%{ }^{\left({ }^{(5)}\right.}$ With increases in greenhouses gases, notably $\mathrm{CO}, \mathrm{HbCO}$ levels may also be elevated for some living in 'polluted' locations. Measurements taken soon after smoking have been reported to be a major contributing factor impacting $\mathrm{HbCO}$ levels (15\%-20\%), and should be considered when determining a 'normal' level for a specific individual. ${ }^{(4)}$ These factors may confound the clinical picture of $\mathrm{CO}$ poisoning cases. Awareness of what constitutes a normal range for HbCO and knowledge of influencing factors can be important for diagnosing $\mathrm{CO}$ poisoning, since the actual blood concentration does not appear to be well correlated with clinical events. ${ }^{(5)}$

Yours sincerely,

John H $\underline{\text { Lange}}^{1}$, Luca Cegolon ${ }^{2}$

${ }^{1}$ Envirosafe Training and Consultants, Pittsburgh, PA, USA, ${ }^{2}$ London School of Hygiene and Tropical Medicine, Department of Infectious Disease Epidemiology, London, UK. Jhlange1@hotmail.com

\section{REFERENCES}

1. Kara H, Bayir A, Ak A, Degirmenci S. Cerebrovascular ischaemia after carbon monoxide intoxication. Singapore Med J 2015; 56:e26-e28.

2. Marshall MD, Kales SN, Christiani DC, Goldman RH. Are reference intervals for carboxyhemoglobin appropriate? A survey of Boston area laboratories. Clin Chem 1995; 41:1434-8.

3. Van Sickle D, Chertow D. Inappropriate reference intervals for carboxyhemoglobin at some Florida hospitals. Clin Chem 2006; $52: 338$.

4. Hampson NB, Scott KL. Use of a noninvasive pulse CO-oximeter to measure blood carboxyhemoglobin levels in bingo player. Respir Care 2006; 51:758-60.

5. US Department of Health and Human Services, Public Health Service, Agency for Toxic Substances and Disease Registry. Toxicological Profile for Carbon Monoxide. 2012, 630-08-0 [online]. Available at: www.atsdr.cdc.gov. Accessed March 5, 2015 